\title{
ОСНОВНІ ДЕФОРМАТИВНІ ВЛАСТИВОСТІ КЕРАМЗИТОБЕТОНІВ
}

ОСНОВНЫЕ

ДЕФОРМАТИВНЫЕ

СВОЙСТВА

КЕРАМЗИТОБЕТОНОВ

\section{THE BASIC DEFORMATION PROPERTIES OF CLAYDITE- CONCRETES}

Кравченко С.А., к.т.н., доц, Постернак О.О., к.т.н., доц. (Одеська державна академія будівництва та архитектури, г. Одеса)

Кравченко С.А., к.т.н., доц, Постернак А.А., к.т.н., доц. (Одесская государственная академия строительства и архитектуры, г. Одесса)

Kravchenko S.A., candidate of technical sciences, docent, Posternak A.A., candidate of technical sciences, docent. (Odessa state academy of civil engineering and architecture)

Наведено результати експериментальних досліджень модуля пружності, усадки та повзучості керамзитобетонів. Описана методика експериментальних досліджень, результати випробувань зразків і їх аналіз, а також обсяг, цілі і результати випробувань.

Приведены результаты экспериментальных исследований модуля упругости, усадки и ползучести керамзитобетонов. Описана методика экспериментальных исследований, результаты испытаний образцов и их анализ, а также объем, цели и результаты испытаний.

The results of experimental studies of the modulus of elasticity, shrinkage and creep of expanded clay concrete are presented. Studies show that the use of lime and active mineral additives and in particular fly ash can reduce the consumption of cement. The method of experimental studies, the results of testing samples and their analysis, as well as the volume, purpose and results of the tests are described. Optimal compositions of expanded clay concretes satisfying the requirements for deformability are obtained. According to the results of experimental studies with $95 \%$ reliability, quadratic regression equations for the modulus of elasticity of expanded clay concrete and expanded clay perlite concrete on multicomponent binder and quartz sand are obtained. Were received regression models of the second order, linking the magnitude of shrinkage deformations and the extent of creep factors of the composition and the conclusion about the possibility of wide regulation of 
extended properties through proper selection of the components of the composition of claydite-concrete on multicomponent binder. Convenient dependences for practical use in determining the deformation of expanded clay concrete on a multicomponent binder are established Carried out researches have allowed to evaluate the main characteristics of the longlasting properties of claydite-concrete on multicomponent binder required for implementation in the prestressed structures of buildings and structures.

Ключові слова:

Деформативність, усадка, повзучість, керамзитобетон, в'яжуче Деформативность, усадка, ползучесть, керамзитобетон, вяжущее. Deformations, shrinkage, creep, claydite-concrete, binder.

Введение. В последние годы внимание сосредоточено на разработке и применении конструкций с использованием новых материалов и компонентов, обладающих улучшенными технологическими и эксплуатационными свойствами.

Лёгкий бетон на пористых заполнителях представляет собой универсальный строительный материал, позволяющий при его рациональном использовании решать многие актуальные задачи современного строительства и одновременно решать экологические, ресурсосберегающие и экономические проблемы за счёт технологических и техногенных отходов при применении и изготовлении местных пористых заполнителей и различных видов вяжущих.

Основным преимуществом бетонов на пористых заполнителях по сравнению с тяжёлым бетоном является пониженная плотность, что позволяет уменьшить массу конструкции и обеспечивает экономические преимущества при возведении фундаментов, особенно для высотных зданий, а также в несущих конструкциях, особенно работающих на изгиб, где собственная масса составляет значительную часть от полной нагрузки [1].

Анализ последних достижений. За последнее время накопилось много исследований прочности и деформаций легких бетонов и конструкций на их основе, приведены в работах М.А. Ахматова, Э.М Бабича, В.Н. Вырового, Б.С. Комисаренко, Р.Л. Маиляна, А.И. Костюка, Н.Я. Спивака, В.Г. Суханова, А.Б. Пирадова и др.

На современном уровне значительный вклад в развитие бетонов с использованием шлака и золы внесли Ш.Т. Бабаев, Е.В. Гончикова, С.А. Высоцкий, Л.И. Дворкин, О.Л. Дворкин, А.Г. Зоткин, С.В Зинченко, Н.Р. Рузиев, А.В. Каляскин, и др., но в основном ресурсосберегающие вопросы за счёт применения промышленных отходов при изготовлении пористых заполнителей и вяжущих рассматриваются для тяжелых бетонов. 
Основная цель статьи заключается в исследовании деформативности опытных образцов из керамзитобетонов при кратковременном и длительном действии нагрузки.

Методика исследования. Материалы, использованные в исследованиях, имели следующие характеристики:

- керамзитовый гравий 5..10 мм, нефракционированный Кулиндоровского индустриального концерна "Инто-Строй”, марки по насыпной плотности М 600, условной прочностью в цилиндре, равной 2,8 ...3,0 МПа;

- песок кварцевый Кременчугского карьера;

- цемент М 400 Криворожского завода - ДСТУ Б В.2.7-112-2002;

- зола-унос Ладыжинской ТЭС - ГОСТ 25818-91;

- известь негашёная Кулиндоровского завода, содержание активной окиси кальция $\mathrm{CaO}-75 \%$;

- гипс строительный - ДСТУ Б В.2.7-104-2000;

- суперпластификатор С-3-ТУ-2481-001-51831493-00.

Анализ литературных источников в подобного ряда исследованиях, а также результаты проведенных предварительных опытов позволили выбрать следующие факторы и назначить уровни их варьирования:

1 - расход цементно-зольной смеси, соотношение $1: 1$, кг $/ \mathrm{M}^{3}-\mathrm{X}_{1}(300 \pm 100)$;

2 - расход извести, кг $/ \mathrm{M}^{3}-\mathrm{X}_{2}(125 \pm 25)$;

3 - агрегатно-структурный фактор $\mathrm{r}-\mathrm{X}_{3}(0,4 \pm 0,1)$.

Обработка результатов эксперимента с целью выявления закономерностей влияния исследуемых факторов $-\mathrm{X}_{1}, \mathrm{X}_{2}, \mathrm{X}_{3}$ на модуль упругости керамзитобетона $f_{c d}$, позволили получить с 95\% надёжностью квадратичные уравнения регрессии $f_{c d}{ }^{28}$.

На основании полученных зависимостей, а также исходя из требований, предъявляемых к лёгким бетонам, производили назначение оптимальных составов керамзитобетона и керамзитоперлитобетона на многокомпонентном вяжущем и кварцевом песке приведенные в табл.1 и табл.2.

Таблица 1

\begin{tabular}{|c|c|c|c|c|c|c|c|c|c|}
\hline \multirow{2}{*}{ 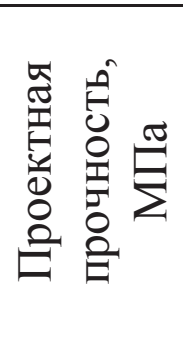 } & \multirow[b]{2}{*}{ 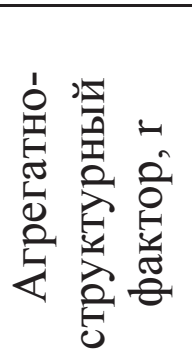 } & \multicolumn{8}{|c|}{ Расход материалов на 1 м $^{3}$ бетона } \\
\hline & & 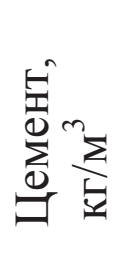 & 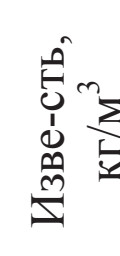 & 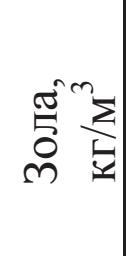 & 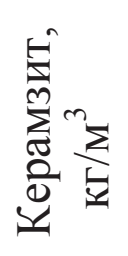 & 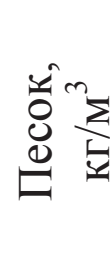 & $\mathscr{E}^{0} \sum^{n}$ & $\tilde{u}^{1} 0^{\circ}$ & 趈 \\
\hline 10 & 0,5 & 100 & 110 & 100 & 495 & 500 & 25 & 0,3 & 205 \\
\hline 12,5 & 0,3 & 110 & 150 & 105 & 460 & 210 & 25 & 0,3 & 225 \\
\hline 15 & 0,3 & 150 & 125 & 145 & 475 & 215 & 25 & 0,3 & 235 \\
\hline 20 & 0,3 & 200 & 105 & 190 & 455 & 205 & 25 & 0,3 & 220 \\
\hline 25 & 0,3 & 220 & 150 & 200 & 460 & 200 & 25 & 0,3 & 230 \\
\hline
\end{tabular}


Таблица 2

\begin{tabular}{|c|c|c|c|c|c|c|c|c|c|}
\hline \multirow{2}{*}{ 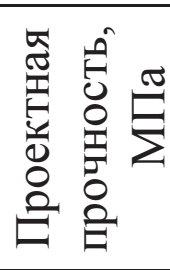 } & \multirow{2}{*}{ 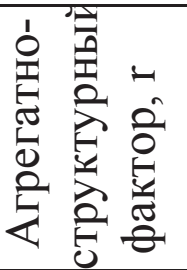 } & \multicolumn{8}{|c|}{ Расход материалов на 1 м ${ }^{3}$ бетона } \\
\hline & & 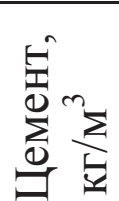 & 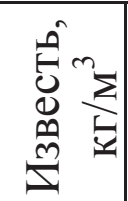 & 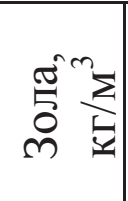 & 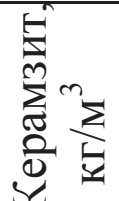 & $\begin{array}{l}5 \\
0 \\
0 \\
0 \\
0\end{array}$ & 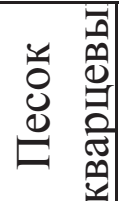 & $\begin{array}{l}d^{\circ} \\
\dot{j} \\
\tilde{j}\end{array}$ & 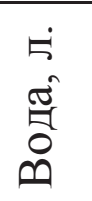 \\
\hline 5,0 & 0,3 & 110 & 160 & 100 & 450 & 70 & 120 & 0,3 & 225 \\
\hline 7,5 & 0,3 & 160 & 130 & 150 & 440 & 80 & 130 & 0,3 & 240 \\
\hline 10,0 & 0,4 & 190 & 130 & 210 & 520 & 140 & 210 & 0,3 & 305 \\
\hline 12,5 & 0,5 & 210 & 150 & 200 & 480 & 195 & 280 & 0,3 & 325 \\
\hline
\end{tabular}

Изучение длительных деформаций свойств бетона осуществлялось на неармированных призматических образцах размерами 100x100x400 мм с неизолированной от высыхания поверхностью. Изучение потерь в арматуре на железобетонных стержневых (размерами 100x100x900 мм) образцах, находящихся под действием центрально приложенных усилий предварительного натяжения и балках размерами 100х220х2200 мм с одиночным армированием, находящихся под действием усилий предварительного натяжения арматуры и внешней длительнодействующей нагрузки. За начало отсчёта деформаций принят возраст, соответствующий моменту достижения бетоном 70\% проектной прочности. При постановке опытов была использована теория планирования эксперимента и математикостатистические методы анализа результатов.

Результаты исследования. По результатам экспериментальных исследований с 95\% надёжностью получены квадратичные уравнения регрессии модуля упругости керамзитобетона и керамзитоперлитобетона на многокомпонентном вяжущем и кварцевом песке в возрасте $\mathrm{t}=1$ п.п., 28, 180 и 360 сутки. Уравнения по $\mathrm{F}$ - критерию Фишера адекватны $\left(F_{\text {ад }}<F_{\text {табл }}\right)$ и имеют информационную ценность $\left(\mathrm{F}_{\mathrm{mH}}>\mathrm{F}_{\mathrm{rasi}}\right)$.

-для керамзитобетона:

$$
\mathrm{E}_{\mathrm{cd}}(1 . \mathrm{m} . \mathrm{n}) \times 10^{-3}=8,1+1,42 \mathrm{X}_{1}+0,26 \mathrm{X}_{2}-1,1 \mathrm{X}_{3}+0,29 \mathrm{X}_{1} \mathrm{X}_{3}+
$$

$$
\begin{aligned}
& 0,37 \mathrm{X}_{1}^{2}-0,15 \mathrm{X}_{2}^{2}+1,74 \mathrm{X}_{2}^{2} ; \\
& \quad \mathbf{E}_{\mathrm{dd}}(28) \times 10^{-3}=8,84+1,6 \mathrm{X}_{1}+0,34 \mathrm{X}_{2}-1,3 \mathrm{X}_{\mathrm{g}}+0,11 \mathrm{X}_{1} \mathrm{X}_{9}-
\end{aligned}
$$

$0,17 \mathrm{X}_{2} \mathrm{X}_{3}+0,2 \mathrm{X}_{1}^{2}-0,19 \mathrm{X}_{2}^{2}+1,95 \mathrm{X}_{3}^{2}$;

$$
\mathbf{E}_{\mathrm{cd}}(180) \times 10^{-3}=9,82+1,7 \mathrm{X}_{1}+0,34 \mathrm{X}_{2}-1,45 \mathrm{X}_{\mathrm{g}}+0,25 \mathrm{X}_{1} \mathrm{X}_{2}+
$$$$
0,22 \mathrm{X}_{1} \mathrm{X}_{9}-0,24 \mathrm{X}_{2} \mathrm{X}_{\mathrm{a}}-0,24 \mathrm{X}_{2}^{2}+2,2 \mathrm{X}_{3}^{2} \text {; }
$$

$$
\mathrm{E}_{\text {ad }}(360) \times 10^{-3}=10,44+1,7 \mathrm{X}_{1}+0,26 \mathrm{X}_{2}-1,4 \mathrm{X}_{3}+0,21 \mathrm{X}_{1} \mathrm{X}_{2}+
$$

$0,35 \mathrm{X}_{1} \mathrm{X}_{3}-0,26 \mathrm{X}_{2} \mathrm{X}_{2}+2,3 \mathrm{X}_{\mathrm{g}}^{2}$.

- для керамзитоперлитобетона: 


$$
\begin{aligned}
& \mathrm{E}_{c d}(1 . \mathrm{m} . \mathrm{\Pi}) \times 10^{-3}=5,82+1,63 \mathrm{X}_{1}+0,27 \mathrm{X}_{2}-1,38 \mathrm{X}_{2}+0,35 \mathrm{X}_{1}^{2}- \\
& 0,34 \mathrm{X}_{2}^{2}+1,49 \mathrm{X}_{3}^{2} ; \\
& \mathrm{E}_{c d}(28) \times 10^{-3}=6,55+1,74 \mathrm{X}_{1}+0,33 \mathrm{X}_{2}-1,54 \mathrm{X}_{9}-0,15 \mathrm{X}_{2} \mathrm{X}_{1}+ \\
& 0,17 \mathrm{X}_{1}^{2}-0,39 \mathrm{X}_{2}^{2}+1,69 \mathrm{X}_{2}^{2} ;
\end{aligned}
$$

$$
\begin{aligned}
& \mathrm{E}_{\mathrm{cd}}(180) \times 10^{-3}=7,33+1,86 \mathrm{X}_{1}+0,3 \mathrm{X}_{2}-1,66 \mathrm{X}_{3}+0,19 \mathrm{X}_{1} \mathrm{X}_{2}- \\
& \quad 0,18 \mathrm{X}_{2} \mathrm{X}_{1}+0,11 \mathrm{X}_{1}^{2}-0,36 \mathrm{X}_{2}^{2}+1,99 \mathrm{X}_{3}^{2} \\
& \mathrm{E}_{\mathrm{cd}}(360) \times 10^{-3}=7,92+1,88 \mathrm{X}_{1}+0,3 \mathrm{X}_{2}-1,61 \mathrm{X}_{3}+0,19 \mathrm{X}_{1} \mathrm{X}_{2}+ \\
& \quad 0,13 \mathrm{X}_{1} \mathrm{X}_{3}-0,19 \mathrm{X}_{2} \mathrm{X}_{3}+0,12 \mathrm{X}_{1}^{2}-0,55 \mathrm{X}_{2}^{2}+2,22 \mathrm{X}_{2}^{2}
\end{aligned}
$$

Из этих уравнений видно, что наибольшее влияние оказывает расход вяжущего $\left(\mathrm{X}_{1}\right.$ и $\left.\mathrm{X}_{2}\right)$ по сравнению $\mathrm{c} \mathrm{r}\left(\mathrm{X}_{3}\right)$, хотя оба они в значительной степени влияют на указанную величину.

Для упрощения квадратичных уравнений регрессии была использована зависимость для описания достаточно надёжной статической связи $\mathrm{y}=E_{\mathrm{cd}}(\mathrm{t})$ и $\mathrm{x}=(B / M K B)+\mathrm{r}$ и был проведен математико-статистический анализ, в результате которого нулевая гипотеза о равенстве нулю коэффициента корреляции $\mathrm{H}_{0}: \rho_{x y}=0$ отвергнута в пользу альтернативной $\mathrm{H}_{0}: \boldsymbol{\rho}_{x y} \neq 0$ при уровне значимости $\alpha=0,05$, что свидетельствует о наличии линейной связи между $E_{\mathrm{cd}}(\mathrm{t})$ и $(B / M K B)+\mathrm{r}$ в каждом из принятых возрастов керамзитобетона.

В результате применения регрессионного анализа для каждого из принятых возрастов керамзитобетонов получены линейные уравнения регрессии вида:

-для керамзитобетона:

$$
\begin{gathered}
\mathrm{E}_{\mathrm{ad}}\left(\mathrm{I}_{1} \bar{\Pi}_{1} \bar{\Pi}_{\mathrm{l}}\right) \times 10^{-3}=19,6-11[(\mathrm{~B} / \mathrm{MKB})+\mathrm{r}] \\
\mathrm{E}_{c d}(28) \times 10^{-3}=21,6-12,3[(\mathrm{~B} / \mathrm{MKB})+\mathrm{r}] \\
\mathrm{E}_{\mathrm{cd}}(180) \times 10^{-3}=23,9-13,7[(\mathrm{~B} / \mathrm{MKB})+\mathrm{r}] \\
\mathrm{E}_{\mathrm{cd}}(360) \times 10^{-3}=23,4-11,7[(\mathrm{~B} / \mathrm{MKB})+\mathrm{r}]
\end{gathered}
$$

- для керамзитоперлитобетона:

$$
\begin{array}{r}
E_{c d}\left(1_{1} \Pi_{1} \Pi_{1}\right) \times 10^{-3}=19,4-12,5[(\mathrm{~B} / \mathrm{MKB})+\mathrm{r}] \\
E_{\mathrm{cd}}(28) \times 10^{-3}=21,1-13,4[(\mathrm{~B} / \mathrm{MKB})+\mathrm{r}] \\
E_{\mathrm{cd}}(180) \times 10^{-3}=23,2-14,5[(\mathrm{~B} / \mathrm{MKB})+\mathrm{r}] \\
E_{\mathrm{cd}}(360) \times 10^{-3}=23,7-14,3[(\mathrm{~B} / \mathrm{MKB})+\mathrm{r}] .
\end{array}
$$

Результаты статистических расчётов свидетельствуют о том, что нулевая гипотеза о равенстве дисперсий обобщённого фактора состава $S_{x^{2}}$, и модуля упругости $S_{y^{2}}$ во всех возрастах керамзитобетона не отвергается. Однако гипотеза о незначимости различия между выборочными 
коэффициентами корреляции $\tau_{x y}$ отвергнута: $Z>Z_{1}-a / 2$. Следовательно, коэффициенты регрессии при обобщённом факторе состава $(B / M K B)+\mathrm{r}$ в линейных уравнениях $\mathbf{E}_{\mathrm{cd}}(\mathbf{1} . \mathbf{m} . \mathbf{\Pi}.) . . \mathbf{E}_{\mathrm{cd}}(360)$ не принадлежат единой генеральной совокупности. Из этого следует, что расход воды оказывает статистически значимое влияние на изменение модуля упругости во времени.

Опытные конечные величины, характеризующие длительную деформативность бетонов в нормальных температурно-влажностных условиях, составили:

$$
\begin{gathered}
\varepsilon_{y c}=(40 \div 60) \times 10^{-5} \\
C_{00}(t, \tau)=(1,251 \div 2,467) \times 10^{-5}
\end{gathered}
$$

Нами были получены регрессионные модели второго порядка, связывающие величины деформаций усадки и меру ползучести с факторами состава и сделан вывод о возможности широкого регулирования длительных свойств путём рационального подбора компонентов состава керамзитобетона на многокомпонентном вяжущем.

$$
\begin{gathered}
\varepsilon_{j x}(360)=\left(0,257 M K B-0,0003 M K B^{2}+163,75 r-147,7 r^{2}-41,31\right) 10^{-5} \\
C_{m}(360)=\left[M K B(1,06 M K B-1133,3) 10^{-5}+r(0,2955 r+2.5015)\right. \\
-0,00422 M K B r+4,751] 10^{-5}
\end{gathered}
$$

где: МКВ (кг) - расход вяжущего на 1 м $^{3}$ бетона;

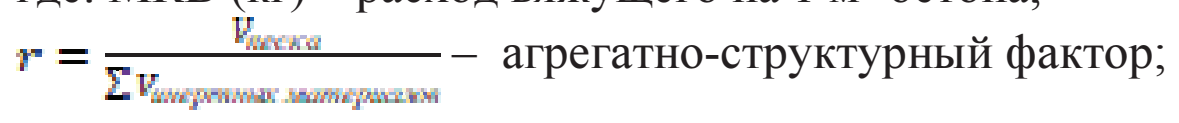

Установлено, что пропаривание позволяет уменьшить деформации усадки на величину, достигающую $31,5 \%$, а меру ползучести - на $2-63 \%$. Снижение меры ползучести за счёт термовлажностной обработки будет тем больше, чем меньше расход цемента и чем выше объём растворной части бетона. Одновременно, пропаривание ведёт к снижению (до 24,8 \%) величин модуля упругости керамзитобетона на многокомпонентном вяжущем.

При одинаковых: составах, прочности и условиях твердения конечные значения деформаций усадки керамзитобетона на многокомпонентном вяжущем и обычного керамзитобетона на кварцевом песке будут одинаковы. Мера линейной ползучести керамзитобетона на многокомпонентном вяжущем на 10 - 15,6\% ниже, чем у обычного керамзитобетона на кварцевом песке.

Изменение во времени величины модуля упругости керамзитобетона на многокомпонентном вяжущем для большинства составов подчиняется типичным для керамзитобетонам закономерностям, отмечавшимися в опытах В.Г. Суханова, А.И. Костюка и И.А. Столевича.

Исключение составляют бетоны с повышенным содержанием растворной части (425 - 550 кг ), модуль упругости который на всём 
протяжении опыта увеличивается. Прирост по отношению к $\boldsymbol{E}_{c d}(28)$ достигает в возрасте 360 суток 5 - 13,5\%. Необходимо отметить, что полученные из опыта значения $E_{c d}(28)$ керамзитобетона на многокомпонентном вяжущем хорошо согласуются с данными ДБН В.2.6 98:2009.

B опытах с керамзитобетонными предварительно напряжёнными сжатыми и изгибаемыми элементами установлено, что при плавной передаче на бетон усилий натяжения стержневой арматуры класса А $400 \mathrm{C}$ сцепление между поверхностью арматуры и бетоном не нарушается.

Величины пластических потерь зависят от значений начальных относительных напряжений сжатия бетона $k_{\sigma}=\sigma_{c} / f_{c d}\left(t_{0}\right)$ и от вида мелкого заполнителя. Форма эпюры напряжений в бетоне тем существеннее сказывается на величинах пластических потерь, чем выше значение $k_{g}$. Величины деформаций бетона верхней зоны и выгибы балок при отпуске натяжения от вида заполнителя не зависят.

Конечные значения усадочных деформаций ненапрягаемых образцов зависят от наличия арматуры и величины коэффициента армирования $\rho_{f}$. С увеличением класса бетона конечные значения $\varepsilon_{l c}$ увеличиваются при $\rho_{f}=0$ и уменшаются при $\rho_{f}>0$. Рост коэффициента армирования ведёт к уменьшению конечних значений $\varepsilon_{y c}$, что связано с усадочными растрескиванием керамзитобетона на многокомпонентном вяжущем. Для оценки потерь от усадки в арматуре предварительно напряжённых элементов могут быть использованы значения $\boldsymbol{z}_{y}$, замеренные на арматуре ненапрягаемых образцов - близнецов.

Связь между полными (усадка плюс ползучесть) потерями в арматуре и начальным уровнем напряжения сжатия керамзитобетона (не превышающим 0,8) определяется линейной зависимостью:

$$
\sigma_{n}(t)=E_{s}\left[\delta k_{z}+\varepsilon_{y z}(t)\right]
$$

где: $E_{s}-$ модуль упругости напрягаемой арматуры;

$\varepsilon_{y c}(t)$ - усадочные деформации, замеренные в возрасте $t$ на арматуре ненапрягаемых образцах - близнецах ;

$\delta$ - коэффициент пропорциональности.

После нагружения балок внешней длительнодействующей нагрузкой прирост $\sigma_{n}(t)$ практически прекращается.

Оптимальные значения начальных относительных напряжений сжатия керамзитобетона на многокомпонентном вяжущем находятся в диапазоне $0,2<k_{\sigma} \leq 0,8$. При этом конечные величины полных потерь в арматуре не превышают $35-38 \% \sigma_{01}$. 


\section{Выводы:}

1. Рецептурно-технологические факторы оказывают существенное влияние на формирование основных свойств керамзитобетона и керамзитоперлитобетона на многокомпонентном вяжущем и кварцевом песке. Учёт влияния указанных факторов с достаточной для практики точностью рекомендуется осуществлять, используя квадратические уравнения регрессии и линейные уравнения.

2. Значения модуля упругости $\mathrm{E}_{\mathrm{cd}}$ отличаются от рекомендуемых ДБН В.2.6 - 98:2009. Поэтому величину $\mathrm{E}_{\mathrm{cd}}$ рекомендуется определять по выражениям (2), (10) и (6), (14).

3. Проведенные исследования позволили оценить основные характеристики длительных свойств керамзитобетона на многокомпонентном вяжущем, необходимые для реализации в преднапряжённых конструкциях зданий и сооружений.

1. Столевич А.С. Конструкционные лёгкие бетоны / А.С. Столевич, С.В. Макаров, И.А Столевич, К.М. Мади, С.А Кравченко// Вісник ОДАБА : зб. наук. праць. - Одеса, 2006. - вип.21. - С. 246-255.

2. Кравченко С.А. Исследование свойств конструкционно-теплоизоляционных лёгких бетонов на пористых заполнителях / С.А. Кравченко, А.А. Постернак // Актуальные научные исследования в современном мире: XXXII Междунар. научн. конф., 26-27 декабря 2017 г., Переяслав-Хмельницкий. // Сб. научных трудов Переяслав- Хмельницкий, 2017. - Вып. 12(32), ч. 1 - С. 129-135.

3. Кравченко С.А. Свойства керамзитобетона на многокомпонентном вяжущем / С.А. Кравченко, А.А. Постернак,А.И. Костюк, И.А.Столевич // Містобудування та територіальне планування: Наук-техн. збірник/-К., КНУБА,2013. Вып48.-536с- Вип. № 48, C. $217-221$.

4. Кравченко С.А. Усадка и ползучесть керамзитобетона на многокомпонентном вяжущем. / С.А. Кравченко, А.С. Столевич, А.А. Постернак, И.А.Столевич // Вісник ОДАБА: зб. наук. праць, вип. №. 44, Одеса, ОДАБА, 2012. - С.320 - 325.

1. Stolevich A.S. Konstruktsionnye legkie betony / A.S. Stolevich, S.V. Makarov, I.A Stolevich, K.M. Madi, S.A Kravchenko// Visnik ODABA : zb. nauk. prats. - Odesa, 2006. vip.21. - S. 246-255.

2. Kravchenko S.A. Issledovanie svoystv konstruktsionno-teploizolyatsionnyh legkih betonov na poristyh zapolnitelyah / S.A. Kravchenko, A.A. Posternak // Aktual'nye nauchnye issledovaniya v sovremennom mire: HKHKHII Mezhdunar. nauchn. konf., 26-27 dekabrya 2017 g., Pereyaslav-Hmelnitskiy. // Sb. nauchnyh trudov - PereyaslavHmelnitskiy, 2017. - Vyp. 12(32), ch. 1 - S. 129-135.

3. Kravchenko S.A. Svojstva keramzitobetona na mnogokomponentnom vyazhushchem / S.A. Kravchenko, A.A. Posternak,A.I. Kostyuk, I.A.Stolevich // Mistobuduvannya ta teritorial'ne planuvannya: Nauk-tekhn. zbirnik/-K., KNUBA,2013. Vyp48.-536s- Vip. № 48, S.217-221.

4. Kravchenko S.A. Usadka i polzuchest' keramzitobetona na mnogokomponentnom vyazhushchem. / S.A. Kravchenko, A.S. Stolevich, A.A. Posternak, I.A.Stolevich // Visnik ODABA: zb. nauk. prac', vip. №. 44, Odesa, ODABA, 2012. - S.320 - 325. 